\title{
Notícias falsas em tempos de pandemia pelo novo coronavírus: uma análise documental
}

Fake News on Coronavirus in the Context of the COVID-19 Pandemic: A Documentary Analysis

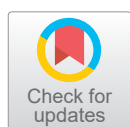

Noticias falsas del nuevo coronavirus en tiempos de pandemia: análisis documental

Como citar este artigo

Alencar, Nadyelle Elias Santos; Lima, Francisca Fabiana Fernandes; Gouveia, Marcia Teles de Oliveira; Silva, Grazielle Roberta Freitas da. Notícias falsas em tempos de pandemia pelo novo coronavírus: uma análise documental. Revista Cuidarte. 2021;12(2):e1297. http://dx.doi.org/10.15649/cuidarte.1297

Revista Cuidarte

Rev Cuid. May - Ago 2021; 12(2): e1297

doij http://dx.doi.org/10.15649/cuidarte.1297

E-ISSN: 2346-3414

(1) Nadyelle Elias Santos Alencar ${ }^{1}$

(1) Francisca Fabiana Fernandes Lima

(1) Marcia Teles de Oliveira Gouveia ${ }^{3}$

(1) Grazielle Roberta Freitas da Silva ${ }^{4}$

1 Universidade Federal do Piauí (UFPI), Teresina, Piauí, Brasil. Autor correspondente. E-mail: nadyelle-elias@hotmail.com Autor Correspondente

2 Universidade Federal do Piauí (UFPI), Teresina, Piauí, Brasil. E-mail: ffabiana-fl@hotmail.com

3 Universidade Federal do Piauí (UFPI), Teresina, Piauí, Brasil. E-mail: marcia06@gmail.com

4 Universidade Federal do Piauí (UFPI), Teresina, Piauí, Brasil. E-mail: grazielle_roberta@yahoo.com.br

\section{Resumo}

Introdução: A infodemia, ou fluxo elevado de informações, apresenta comportamento similar aos vírus, disseminam-se de pessoa a pessoa e representam um novo desafio às autoridades de saúde. Objetiva-se analisar as notícias falsas veiculadas no contexto da pandemia pelo novo coronavírus. Materiais e métodos: Pesquisa documental realizada com base no portal de notícias do Ministério da Saúde do Brasil intitulado "Saúde sem Fake News". Foram identificadas as publicações ocorridas de dezembro/2019 a março/2020, por meio das seguintes palavraschave: coronavírus e COVID-19. Para a apreciação dos dados, foi adotada a análise de conteúdo proposta por Bardin. Resultados: Foram identificadas 66 publicações, com o total de 92 fake news. A análise revelou as características comuns às fake news, dentre elas: manchetes e imagens chamativas, dados alarmantes e disseminação cíclica. Além disso, as mídias sociais despontaram como importante via de disseminação e, para conferir efeito de verdade ao dito, a atribuição da autoria a órgãos ou profissionais da saúde foi comum. As notícias foram categorizadas em seis grupos temáticos: métodos para prevenção $(32,6 \%)$ e história natural da doença $(28,2 \%)$ foram os mais frequentes. Discussão: Observase o interesse crescente por temas relacionados à disseminação de informações sobre o novo coronavírus e as investigações ao redor do mundo destacam a importância da atuação do Governo e dos órgãos da saúde na identificação e combate às notícias falsas. Conclusões: As fake news relacionadas ao novo coronavírus ameaçam a saúde individual e coletiva, abordam temáticas diversas e apresentam potencial de dano à saúde física e mental.

Palavras chave: Coronavirus; Pandemias; Educação em Saúde; Notícias; Disseminação de Informação.

Recebido: junhio 08 de 2020

Aceito: dezembro 17 de 2020

Publicado: abril 30 de 2021 $\square *$ Correspondencia

Nadyelle Elias Santos Alencar

E-mail: nadyelle-elias@hotmail.com 


\title{
Fake News on Coronavirus in the Context of the COVID-19 Pandemic: A Documentary Analysis
}

\begin{abstract}
Introduction: Infodemic, defined as a high flow of information, has a similar behavior to that of viruses, as it quickly spreads from person to person, which represents a new challenge for healthcare authorities. The objective is to analyze fake news published in the context of the COVID-19 pandemic. Materials and Methods: A documentary research was conducted based on the Brazilian Ministry of Health news website titled "Health without fake news". Coronavirus and COVID-19 were the keywords used to identify news published between December 2019 and March 2020. For data visualization, the content analysis approach developed by Bardin was applied. Results: 66 publications with a total of 92 fake news were identified. The analysis found common characteristics among fake news such as the use of flashy headlines and images, alarming data and circular diffusion. In addition, social networks emerged as an important means of diffusion in which, in order to give a sense of truthfulness to news, it was common to attribute the authorship of fake news to healthcare organizations or professionals. News articles were classified into six thematic groups in which prevention methods (32.6\%) and natural history of the disease (28.2\%) were the most common topics. Discussion: There is growing interest in topics related to the diffusion of information about coronavirus. Global research points out the importance of identifying and combating fake news by government and healthcare agencies. Conclusions: Fake news related to coronavirus poses a threat to individual and collective health, addresses a variety of issues and carries potential harm to physical and mental health.
\end{abstract}

Key words: Coronavirus; Pandemics; Health Education; News; Information Dissemination.

\section{Noticias falsas del nuevo coronavirus en tiempos de pandemia: análisis documental}

\section{Resumen}

Introducción: La infodemia, entendido como el alto flujo de información, presenta un comportamiento similar al de los virus, ya que se propaga de persona a persona, lo que representa un nuevo reto para las autoridades sanitarias. El objetivo es analizar las noticias falsas publicadas en el contexto de la pandemia por el nuevo coronavirus. Materiales y métodos: Se realizó una investigación documental basada en el portal de noticias del Ministerio de Salud de Brasil con el título de "Salud sin noticias falsas". Las palabras claves utilizadas para identificar las publicaciones realizadas entre diciembre de 2019 y marzo de 2020 fueron coronavirus y COVID-19. Para la visualización de los datos, se incluyó el análisis de contenido propuesto por Bardin. Resultados: Se identificaron 66 publicaciones con un total de 92 noticias falsas. En el análisis se revelaron las características comunes de las noticias falsas como el uso de titulares e imágenes llamativas, datos alarmantes y difusión cíclica. Así mismo, las redes sociales surgieron como una importante vía de difusión en las que, para dar una sensación de veracidad a estas noticias, era habitual atribuir la autoría de estas a organismos o profesionales sanitarios. Las noticias se clasificaron en seis grupos temáticos, entre los que se encuentran los métodos de prevención (32.6\%) y la historia natural de la enfermedad (28.2\%) como los más frecuentes. Discusión: Se observa un creciente interés en los temas relacionados con la difusión de información sobre el nuevo coronavirus y las investigaciones a nivel mundial señalan la importancia de identificar y combatir las noticias falsas por parte del gobierno y las agencias de salud. Conclusiones: Las noticias falsas relacionadas con el nuevo coronavirus representan una amenaza para la salud individual y colectiva, abordan diversas temáticas y conllevan daños potenciales para la salud física y mental.

Palabras clave: Coronavirus; Pandemias; Educación en Salud; Noticias; Difusión de la Información. 


\section{Introdução}

No século XX, a Terceira Revolução Industrial, também conhecida como "era digital" ou "era da informação", promoveu mudanças socioeconômicas e políticas, incorporando velocidade ao modo de viver da população. É nesse contexto que surge a cibercultura, manifestação vital das sociedades baseada na fluidez de informações e na hiperatividade informacional'.

Diante desse fluxo social intenso, as notícias falsas, popularmente conhecidas pelo termo em inglês fake news, são cada vez mais comuns e estão presentes em quase todos os contextos sociais. Conceitualmente, as fake news representam notícias ou informações inverídicas que, de modo geral, suscitam medo e/ou ansiedade na população. Além disso, podem possuir interesses políticos, financeiros ou conter elementos de controle social².

As notícias falsas possuem raízes antigas, mas a sua disseminação atingiu outro patamar com a democratização da internet e popularização das plataformas de mídias sociais. Atualmente, qualquer pessoa, através de um simples dispositivo conectado à internet, é capaz de criar e compartilhar informações sem que seja requisitada ou atestada a sua veracidade ${ }^{3}$.

Dados sobre o uso das Tecnologias de Informação e Comunicação (TIC) nos domicílios brasileiros, em 2018, expõem o crescimento no número de usuários de internet na última década. Em 2009, apenas 39\% dos brasileiros possuíam acesso à internet enquanto que em 2018 esse número alcançou a marca de 70\%, o que representa mais de 126 milhões de indivíduos com idade igual ou superior a dez anos ${ }^{4}$.

Acrescenta-se que a ciência e a saúde são especialmente vulneráveis à (re)produção de conteúdos falsos ${ }^{5}$. Nesse contexto, as fakes news geralmente alertam para fatos improváveis, curas milagrosas ou desaprovação de algum método de prevenção ou tratamento de saúde. São verdadeiros "vírus de informações" capazes de prejudicar a saúde individual e coletiva ${ }^{6}$. E, diante de alguma doença grave ou ameaçadora, o alastramento dessas informações é ainda mais rápido?.

Baseado no exposto, desde que foi descoberto em dezembro de 2019, e sobretudo após receber o status de pandemia em março de $2020^{8}$, o novo coronavírus (SARS CoV2), que causa a doença COVID-19, tem sido foco das fake news. O vírus recém identificado, com características a serem melhor esclarecidas, possui elevado poder de transmissão, capacidade de provocar quadro de infecção pulmonar grave e poder de sobrecarregar os sistemas de saúde ao redor do mundo. Essas são apenas algumas das características que tornam as populações temerosas.

Diante dos medos e incertezas, as informações falsas encontram espaço para disseminação. Assim, paralelo à pandemia pelo novo coronavírus, uma epidemia global de desinformações representa séria ameaça à saúde pública. O fluxo elevado de informações, intitulado infodemia, apresenta comportamento similar aos vírus, disseminam-se de pessoa a pessoa e representam um novo desafio às autoridades de saúde. Por isso, apenas informar não é o suficiente, é necessário identificar e combater as notícias falsas e suas principais fontes ${ }^{10}$.

As fake news ainda representam problemas em busca de solução. No Brasil, o Ministério da Saúde (MS), no intuito de checar os fatos e desmentir essas verdades inventadas criou uma página na internet intitulada "Saúde sem Fake News". Trata-se de uma biopolítica que, ao combater a disseminação de notícias falsas, visa garantir a integridade da saúde da populaçãó. 
O presente estudo objetiva analisar as principais notícias veiculadas na página "Saúde sem Fake News" no contexto da pandemia pelo novo coronavírus, SARS-CoV-2.

\section{Materiais e Métodos}

Pesquisa documental de abordagem qualitativa, caracterizada pela utilização de documentos impressos ou eletrônicos capazes de comprovar algum fato ou acontecimento e elaborado com finalidades diversas, dentre elas, a comunicação ${ }^{11}$.

A pesquisa foi realizada com base em documentos eletrônicos publicados no portal de notícias do MS intitulado "Saúde Sem Fake News" (disponível em https://www.saude.gov.br/fakenews). A referida página foi criada em 2018 e tem como escopo o combate às fake news. Por meio de um WhatsApp exclusivo do MS, no (61)99289-4640, qualquer cidadão pode enviar notícias e informações duvidosas que tiver acesso. Ao Ministério cabe atestar ou não a veracidade das informações por meio de publicações no referido portal e em seus perfis nas redes sociais.

A busca aconteceu durante o mês de março de 2020 e foi realizada por meio das seguintes palavras-chave: "coronavírus" e "COVID-19". Importante ressaltar que o procedimento metodológico para a exploração do material e tratamento dos resultados foi realizado a partir da revisão por pares, com posterior comparação e eliminação das inconsistências, de modo a garantir o rigor científico e a confiabilidade das informações obtidas.

Como foco do estudo, foram levantadas as publicações ocorridas entre os meses de dezembro/2019 a março/2020. A delimitação da data inicial para o recorte temporal faz referência ao surgimento dos primeiros casos e ao início da disseminação de informações sobre a doença no mundo.

Foram incluídas as publicações veiculadas no referido portal que fizessem referência à pandemia pelo novo coronavírus. As postagens que não apresentaram fake news, apenas atestavam como verdadeira uma informação compartilhada, foram excluídas.

Para a organização e posterior apreciação, os dados foram compilados em uma planilha no programa Microsoft Excel. Os indicadores para a coleta dos dados estão definidos a seguir: 0 título, a(s) fake news veiculada(s), a justificativa do MS, a fonte atribuída, o meio de divulgação/ compartilhamento e a data de publicação.

Foi adotada a análise de conteúdo proposta por Bardin, técnica objetiva e sistemática de organização de dados. A análise perfez, portanto, três etapas: 1)pré-análise, contato inicial e seleção dos documentos a serem analisados, elaboração de objetivos e hipóteses, definição de indicadores de coleta; 2)exploração do material, processo de codificação e categorização do corpus textual resultante da coleta de dados; 3)tratamento dos resultados, interpretações inferenciais e reflexivas ${ }^{12}$.

Por tratar-se de uma pesquisa do tipo documental que faz uso de dados de domínio público, não houve a necessidade de submissão ao Comitê de Ética em Pesquisa, conforme as diretrizes da Resolução 466/12 do Conselho Nacional de Saúde. 


\section{Resultados}

A partir da busca com base nas palavras-chave definidas, foram identificadas 70 publicações ocorridas no período de dezembro de 2019 a março de 2020 na página "Saúde sem Fake News" do MS. Dessas, quatro foram descartadas, por não apresentar uma fake news, totalizando 66 publicações avaliadas. A Figura 1 traz a progressão do número de publicações ao longo dos meses.

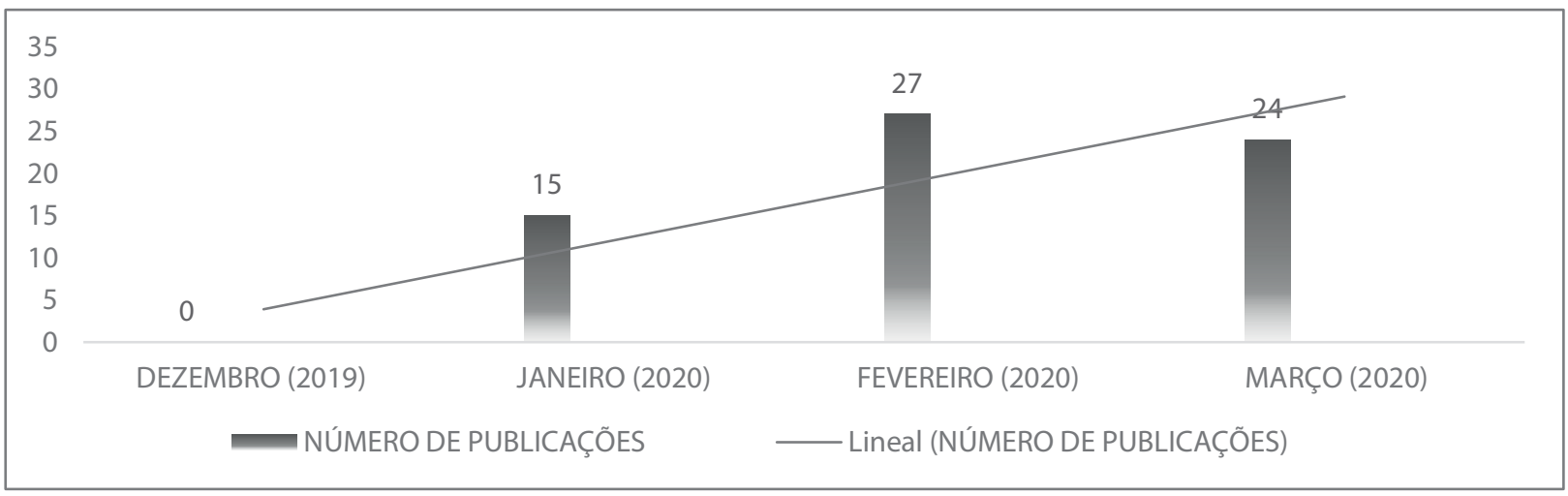

\section{Figura 1. Publicações sobre o novo coronavírus na página Saúde Sem Fake News de dezembro/2019 a março/2020.}

Fonte: elaboração própria.

A análise global das publicações revelou as características assumidas pelas fake news publicitadas, a saber: dados alarmantes, manchetes e imagens chamativas, promessa de cura e imunização milagrosas, erros ortográficos grotescos, além do uso de recursos audiovisuais e disseminação cíclica, com reaparecimento esporádico de notícias. Ademais, cerca de $50 \%$ das publicações foram reproduzidas por meio de mídias sociais, em especial o WhatsApp, e aproximadamente $41 \%$ tiveram a fonte atribuída a profissionais da saúde, pesquisadores, Governo ou MS.
A análise global das publicações revelou as características assumidas pelas fake news publicitadas, a saber: dados alarmantes, manchetes e imagens chamativas, promessa de cura e imunização milagrosas, erros ortográficos grotescos, além do uso de recursos audiovisuais e disseminação cíclica, com reaparecimento esporádico de notícias.

Em relação ao teor das notícias, seis categorias temáticas foram delineadas (Tabela 1). As categorias mais frequentes anunciavam métodos para prevenção e imunização contra a Covid-19 $(32,6 \%)$, tentavam narrar a história natural da doença ou declaravam falsas informações sobre o novo coronavírus e a infecção associada a ele $(28,2 \%)$. Também foram registrados: dados alarmantes sobre o número de casos, propostas de tratamentos e curas milagrosas, questões políticas, e método diagnóstico. Em virtude da possibilidade de articular diferentes informações falsas em uma única publicação, o número de fake news ultrapassa a quantidade de publicações. 
Tabela 1. Categorização temática das notícias sobre o novo coronavírus publicadas na página Saúde sem Fake News de dezembro/2019 a março/2020.

\begin{tabular}{lcc}
\hline Temáticas & $\mathbf{n}$ & $\mathbf{\%}$ \\
\hline Prevenção e imunização & 30 & $32,6 \%$ \\
História natural, característica do vírus e da doença & 26 & $28,2 \%$ \\
Número de casos & 17 & $18,5 \%$ \\
Tratamento e curas milagrosas & 10 & $10,9 \%$ \\
Questões políticas & 08 & $8,7 \%$ \\
Diagnóstico & 01 & $1,1 \%$ \\
Total & $\mathbf{9 2}$ & $\mathbf{1 0 0 \%}$ \\
\hline
\end{tabular}

A história natural da doença foi foco de discussão em $28,2 \%$ das fake news analisadas. Algumas notícias associavam o novo coronavírus ao Vírus da Imunodeficiência Humana (HIV) ou ao uso de inseticidas, além de afirmarem que o SARS-CoV-2 foi criado em laboratório. Também foi disseminada a informação de que o vírus apresenta baixa resistência a temperaturas superiores a $26-27^{\circ} \mathrm{C}$. O tempo de permanência do vírus no ambiente, formas de transmissão, taxa de letalidade e graves complicações associadas à COVID-19 também foram foco das fake news.

Na categoria temática mais frequente, prevenção e imunização, foram identificados métodos caseiros tais como: ingestão frequente de líquidos quentes e elevação do consumo das vitaminas $C$ e $D$ e própolis. Outras notícias apresentavam propostas de imunização por meio da unção com óleo consagrado e banho com cal virgem. Além disso, foi questionada a indicação do uso de álcool em gel para a prevenção contra o vírus.

Sobre o tratamento da COVID-19, as fake news compartilhavam receitas caseiras que, de modo similar aos métodos de prevenção, recomendavam o consumo de líquidos quentes. Ainda, foi anunciada a descoberta de fármacos eficazes contra o vírus.

O diagnóstico da COVID-19 também foi alvo das fake news. Segundo a notícia propalada, o diagnóstico precoce da doença poderia ser feito por meio de um teste respiratório simples que, caso fosse concluído com sucesso, atestaria a ausência da infecção.

Outro grupo de notícias traz manchetes alarmantes sobre o número de casos do novo coronavírus. A maioria declarava os primeiros indivíduos que testaram positivo para COVID-19 no Brasil, outras afirmavam a elevação desmedida na quantidade de casos.

Questões políticas também estiveram transversalmente discutidas pelas notícias falsas sobre o novo coronavírus. Muitas delas acusavam o Governo de mascarar a real situação da doença. Outra, criticou a segurança do aplicativo oficial do Governo, "Coronavírus-SUS".

\section{Discussão}

O presente estudo apresenta o panorama sobre as principais fake news que circularam no Brasil durante os três primeiros meses após o surgimento do novo coronavírus. Além de retratar o padrão de características comuns à maioria das publicações, também foi discutido o teor das notícias por meio de seis categorias temáticas. 
É possível observar o crescimento acentuado no número de publicações, o que coincide com a fluidez dos dados sobre o novo coronavírus que, enquanto objeto de investigações recentes e sem evidências definitivas, torna-se campo fértil para a proliferação das não verdades. Nesse contexto, sobressai a importância da atuação do MS frente ao combate às fake news e com vistas à amenização de possíveis danos à saúde.

Investigações ao redor do mundo destacam a importância da atuação do Governo e dos órgãos da saúde na identificação e combate às notícias falsas ${ }^{13}$, bem como na garantia do acesso a informações baseadas em evidências ${ }^{10}$. Em seus posicionamentos, o MS preza pelo conhecimento científico e, além de contestar o teor de verdade das notícias compartilhadas, também assume função pedagógica ao instruir a população acerca dos cuidados em saúde. Exerce, portanto, um contorno biopolítico que orienta enquanto nega ou defende um posicionamento ${ }^{6}$.

Em relação às suas características, as fake news geralmente demonstram sinais. A importância em reconhecer o perfil comum às notícias falsas foi discutido por um estudo realizado na Índia, com 758 profissionais da saúde, dos quais 50\% afirmaram ter dificuldade em diferenciar as notícias falsas das verdadeiras e 33\% afirmaram que as desinformações interferem na sua tomada de decisão ${ }^{14}$.

Similar às características demonstradas no presente estudo, na Irlanda, as fake news espalharamse sobretudo por meio das mídias sociais e aplicativos de mensagens. Além disso, utilizavam discurso apelativo e, através da persuasão, aumentavam a probabilidade da informação ser compartilhada. Também foi observado o uso do tom alarmista que corroborou para a instalação do medo e pânico no país ${ }^{15}$.

Outra característica bastante comum entre as fake news é a atribuição da autoria a profissionais e órgãos governamentais com notório saber, na tentativa de conferir efeito de verdade ao dito. Ademais, muitas notícias falsas adotam recursos audiovisuais e através de discursos simples, de fácil adesão, conferem maior alcance à informação falsa ${ }^{6}$.

Sobre os meios de propagação, as mídias sociais demonstram apego às informações espetacularizadas, sem compromisso com a verdade, e por isso tornam-se importantes veículos para a (re)produção de fake news ${ }^{1}$. Importante mencionar que, por ser um meio de comunicação de fácil manuseio, o WhatsApp é um elemento fundamental de socialização para idosos ${ }^{4}$. Desse modo, no contexto do novo coronavírus e do seu potencial de gravidade para indivíduos com idade acima de 60 anos $^{16}$, é preciso analisar, de modo diferenciado, o impacto das fake news na saúde desse grupo populacional.

Em relação ao modo de disseminação, as fake news apresentam comportamento cíclico, aparecem, desaparecem e podem retornar ao foco tempo depois'. O raio de alcance dos esclarecimentos fornecidos por órgãos oficiais ou profissionais da saúde é inferior ao poder de difusão das fake news e, para combatê-las, seria necessário restituir a informação verdadeira na mesma proporção em que a notícia falsa foi compartilhada ${ }^{6}$. Por essa razão, em alguns casos, o MS teve que realizar diferentes publicações para negar informações já desmentidas anteriormente.

No que tange às categorias temáticas, no presente estudo, observou-se o interesse por temas relacionados à origem do vírus, métodos diagnósticos, prevenção e tratamento, além de dados alarmantes e questões políticas. Temas concordantes foram observados em uma pesquisa que 
analisou postagens relacionadas à COVID-19 no Twitter e identificou quatro temas centrais: origem do vírus; suas fontes e modos de transmissão; impactos no indivíduo, países e economia; formas de mitigar a doença. Os achados também denunciaram a necessidade de maior proatividade das autoridades de saúde pública no combate à disseminação das fake news ${ }^{17}$.

Em consonância, na Itália, observou-se o interesse crescente por temas relacionados ao novo coronavírus entre os meses de janeiro e março de 2020. Os assuntos de maior destaque foram: sintomas da doença, métodos de prevenção (uso de máscaras e desinfetantes) e boletins de saúde, com destaque para o grande número de informações falsas identificadas ${ }^{18}$.

O novo coronavírus causa a doença classificada como COVID-19e, até onde se tem conhecimento, teve os seus primeiros casos na China, em dezembro de 2019. Entretanto, a história natural da doença ainda não está esclarecida. Sabe-se que o vírus apresenta elevada transmissibilidade e provoca desde casos leves a casos muito graves de síndrome respiratória, com aumento da letalidade em indivíduos acima dos 60 anos de idade ${ }^{16}$.

Diante das incertezas ainda existentes sobre a doença, muitas fake news tentavam gerar alarde ao atribuir a sua origem à criação em laboratório, ou ainda, pela sua comparação ao HIV. E mesmo sendo consenso entre cientistas ao redor do mundo que o vírus teve origem natural, provavelmente de uma espécie animal, teorias como essas continuam a existir ${ }^{19}$. Por outro lado, na tentativa de minimizar o potencial de infecção do vírus, notícias afirmavam a sua baixa resistência a temperaturas superiores a $26-27^{\circ} \mathrm{C}$.

Sobre os métodos propostos para prevenção e tratamento da COVID-19, destacam-se as receitas caseiras que, em sua maioria, recomendavam a ingestão frequente de líquidos quentes. Essa orientação apresenta relação direta com outra fake news anteriormente discutida, a de que o vírus possui baixa resistência a temperatura. Isso leva a inferir que, muitas vezes, a circulação de uma notícia falsa embasa a criação de outras fake news, levando a um ciclo contínuo de propagação.

Destaca-se que, enquanto algumas recomendações são inofensivas, outras representam potencial de ameaça à integridade física ${ }^{19}$. A exemplo, uma das fake news indicava o banho com cal virgem, substância química utilizada na construção civil, para imunização contra o vírus. Além disso, foi questionada a indicação do uso de álcool em gel, método simples e eficaz para a prevenção e controle de infecções ${ }^{20}$. Nesse sentido, desaconselhar a adoção de métodos eficazes, ao tempo em que se estimula a prática nada ou pouco embasada de métodos obsoletos, é um desserviço à saúde coletiva.

Além disso, foi anunciada a descoberta de fármacos eficazes contra o vírus, notícia esta que implicou em um grande número de danos correlatos. Primeiro, a recomendação estimulou o uso indiscriminado dessas medicações. Segundo, a elevada demanda implicou em escassez e prejudicou o tratamento dos que delas necessitavam. Isso corrobora para a inferência de que a disseminação de fake news contribui para complicações e danos severos à saúde individual e coletiva ${ }^{1}$.

Em relação ao diagnóstico da COVID-19, a orientação para a realização de um teste respiratório simples representa mais uma tentativa de minimizar a gravidade da doença, o que pode retardar a procura por atendimento especializado e contribuir para o agravamento do estado de saúde. O MS contesta a denotação simplista atribuída ao diagnóstico e esclarece sobre a necessidade de avaliação clínica associada à realização de exames laboratoriais ${ }^{16}$. 
Ademais, manchetes alarmantes em referência ao número de casos foram observadas. Notícias como essas são frequentes diante de um cenário de incerteza, o que corrobora para o agravamento do medo e da ansiedade, sobretudo diante da exposição exagerada a informações. Surge, assim, um grupo de indivíduos nomeados cibercondríacos que, em referência aos hipercondríacos (vício em doenças e medicamentos), representam pessoas viciadas em internet e no consumo compulsivo de informações por meio dela. Portanto, alerta-se para o perigo associado à exposição excessiva a informações, com reflexos negativos para a saúde física e mental, especialmente no contexto de uma pandemia ${ }^{1}$.

No Curdistão Iraquiano, investigação com 516 indivíduos revelou que a maioria dos adultos jovens, de 18 a 35 anos, enfrentavam distúrbios de ansiedade relacionado à COVID-19. Além disso, o pânico e a ansiedade estiveram correlacionados ao uso exacerbado de mídias sociais ${ }^{21}$. Do mesmo modo, na China, quadros de ansiedade, depressão e estresse foram maiores entre aqueles com maior engajamento nas redes sociais ${ }^{22}$.

A pandemia tem provocado, ao redor do mundo, impactos a diversos setores: escolas e espaços públicos foram fechados, o distanciamento social foi estabelecido e a rotina diária dos indivíduos mudou drasticamente, gerando os sentimentos de insegurança, incerteza, isolamento e abandono ${ }^{9}$. Nesse sentido, embora os aspectos biológicos sejam o foco da ciência enquanto perdurar a crise, os efeitos psicológicos também devem ser mensurados e, se possível, prevenidos.

Questões políticas também estiveram relacionadas à propagação das notícias falsas sobre o novo coronavírus. As motivações para a (re)produção de fake news são inúmeras e o embate político, sem dúvidas, é uma delas. Em geral, são informações que causam confusão, gera medo e ameaçam a eficiência das estratégias de mitigação da doença ${ }^{19}$.

As desinformações sobre o novo coronavírus apresentam potencial de dano, direto ou indireto, à saúde. Por representar ameaça à integridade física, especial atenção deve ser destinada àquelas que divulgam métodos para a prevenção ou tratamento da doença. Além disso, as fake news que tumultuam e geram incerteza na população são responsáveis pela elevação da ansiedade e agravamento de quadros de sofrimento psíquico ${ }^{9}$.

O número de investigações sobre as fake news no contexto da pandemia pelo novo coronavírus está em ascensão. Recomendações atuais sugerem que, por tornarem as pessoas vulneráveis à adoção de práticas sem base científica, as notícias falsas devem ser identificadas e suprimidas ${ }^{13}$. O combate a essas notícias envolve a divulgação de informações oficiais para a propagação de mensagens curtas e diretas que orientem a tomada de decisão ${ }^{23}$.

Diante do exposto, constata-se que as informações falsas representam ameaça à saúde e ações educativas devem ser desenvolvidas para sucumbi-las. A informação, seja ela falsa ou verdadeira, molda o conhecimento humano, influencia a percepção da realidade e exerce poder sobre os hábitos de vida das pessoas ${ }^{1}$. Desse modo, as intervenções educativas devem aproveitar o potencial positivo da informação para promover o uso consciente dos meios de comunicação, bem como para alertar sobre os malefícios associados à criação e/ou disseminação de uma notícia da qual não se conhece a fonte ou a veracidade ${ }^{20}$.

Desse modo, as intervenções educativas devem aproveitar o potencial positivo da informação para promover o uso consciente dos meios de comunicação, bem como para alertar sobre os malefícios associados à criação e/ou disseminação de uma notícia da qual não se conhece a fonte ou a veracidade ${ }^{20}$ 
Os resultados deste estudo referem-se à análise de publicações ocorridas em um recorte temporal curto, portanto, requer cautela na generalização dos resultados. Além disso, foi utilizada apenas a página do MS como fonte para a coleta de dados sobre as fake news, o que não significa que elas retratem fielmente o cenário das informações falsas disseminadas no Brasil durante os meses investigados.

\section{Conclusões}

As fake news relacionadas ao novo coronavírus apresentaram comportamento ascendente em número de publicações. Em relação às suas características, foram observados sinais de alerta para a sua identificação, tais como: manchetes e imagens chamativas, dados alarmantes, promessa de cura e imunização milagrosas, além de erros ortográficos grotescos.

Além disso, as notícias falsas apresentaram elevada propagação por meio das mídias sociais, com disseminação cíclica e atribuição da autoria a órgãos ou profissionais da área da saúde na tentativa de conferir efeito de verdade ao dito. Salienta-se o potencial de dano, direto ou indireto, associado à propagação de notícias inverídicas, capazes de interferir e promover desajustes à saúde física e mental. Assim, torna-se necessária a conscientização para a prevenção dos malefícios associados à criação e/ou disseminação das fake news.

\section{Referências}

1. Maia MR, Biolchini JCA. Hyperinformation in the digital age: validation of health information. P2p \& Inovação. 2019;6(1):285-300. https://doi.org/10.21721/p2p.2019v6n1.p285-300

2. Kitta A. Alternative Health Websites and Fake News: Taking a Stab at Definition, Genre, and Belief. J Am Folk. 2018;131(522):405-412. https://doi.org/10.5406/jamerfolk.131.522.0405

3. De Keersmaecker J, Roets A. 'Fake news': Incorrect, but hard to correct. The role of cognitive ability on the impact of false information on social impressions. Intelligence. 2017;65:107-10. https://doi.org/10.1016/j.intell.2017.10.005

4. Brazilian Internet Steering Committee. Brazilian Network Information Center.

5. Survey on the use of information and communication technologies in brazilian households: ICT households 2018. São Paulo (Brazil): Brazilian Internet Steering Committee, 2019. Available from: https://www.cetic.br/media/docs/publicacoes/2/12225320191028-tic_dom_2018_livro_eletronico.pdf

6. Merchant RM, Asch DA. Protecting the Value of Medical Science in the Age of Social Media and "Fake News". JAMA. 2018;320(23):2415-2416. https://doi.org/10.1001/jama.2018.18416

7. Silva FV, Silva Junior J. Mentiras sinceras (não) me interessam: estratégias biopolíticas do Ministério da Saúde no combate às fake news. Intersecções. 2019;27(1):226-46. Disponível em: URL: https://revistas.anchieta.br/index.php/Revistalnterseccoes/article/view/1395/1277

8. Henriques CMP. Two epidemics: the yellow fever and a lack of information. Reciis - Rev Eletron Comun Inf Inov Saúde. 2018;12(1):9-13. http://dx.doi.org/10.29397/reciis.v12i1.1513

9. World Health Organization. Coronavirus disease 2019 (Covid-19): Situation Report-52. 2020 [cited 2020 apr 7]. Available from: https://www.who.int/docs/default-source/coronaviruse/ situation-reports/20200312-sitrep-52-Covid-19.pdf?sfvrsn=e2bfc9c0_4

10.Ornell F, Schuch JB, Sordi AO, Kessler FHP. "Pandemic fear" and Covid-19: mental health burden and strategies. Braz J Psychiatry. 2020; 42(3): 232-5.

https://doi.org/10.1590/1516-4446-2020-0008 
11.Zarocostas J. How to fight an infodemic. The Lancet. 2020; 395(10225):676. https://doi.org/10.1016/S0140-6736(20)30461-X

12.Gil AC. Como elaborar projetos de pesquisa. $6^{\circ}$ ed. São Paulo (BR): Atlas; 2017.

13.Bardin L. Análise de conteúdo. Lisboa (PT): Edições 70; 2006.

14.Kulkarni P, Prabhu S, D SK, Ramraj B. Covid-19-infodemic overtaking pandemic? Time to disseminate facts over fear. Indian J Comm Health. 2020;32(2-Special Issue):264-8. Available from: https://www.iapsmupuk.org/journal/index.php/IJCH/article/view/1455/1003

15.Datta R, Yadav AK, Singh A, Datta K, Bansal A. The infodemics of COVID-19 amongst healthcare professionals in India. Medical Journal Armed Forces India. 2020 May: 1-8. https://doi.org/10.1016/j.mjafi.2020.05.009

16.0'Connor C. Going viral: doctors must tackle fake news in the covid-19 pandemic. BMJ. 2020;369:m1587. https://doi.org/10.1136/bmj.m1587

17.Brasil. Ministério da Saúde. Secretaria de Atenção Primária à Saúde. Protocolo de manejo clínico do coronavírus (Covid-19) na atenção primária à saúde. Brasília-DF (BR): Ministério da Saúde, 2020. Disponível em: https://www.saude.gov.br/images/pdf/2020/marco/20/20200318-ProtocoloManejo-ver002.pdf

18.Abd-Alrazaq A, Alhuwail D, Househ M, Hamdi M, Shah Z. Top Concerns of Tweeters During the COVID-19 Pandemic: Infoveillance Study. J Med Internet Res. 2020;22(4):e19016. https://doi.org/10.2196/19016

19.Rovettta A, Bhagavathula AS. COVID-19-Related Web Search Behaviors and Infodemic Attitudes in Italy: Infodemiological Study. JMIR Public Health Surveill. 2020;6(2):e19374. https://doi.org/10.2196/19374

20.Mian, A., Khan, S. Coronavirus: the spread of misinformation. BMC Med. 2020; 18(83). https://doi.org/10.1186/s12916-020-01556-3

21.Peters A, Tartari E, Lotfinejad N, Parneix P, Pittet D. Fighting the good fight: the fallout of fake news in infection prevention and why context matters. $J$ Hosp Infect. 2018;100:365-370. https://doi.org/10.1016/j.jhin.2018.08.001

22.Ahmad AR, Murad HR. The Impact of Social Media on Panic During the COVID-19 Pandemic in Iraqi Kurdistan: Online Questionnaire Study. J Med Internet Res. 2020;22(5):e19556. https://doi.org/10.2196/19556

23.Chao M, Xue D, Liu T, Yang H, Hall BJ. Media use and acute psychological outcomes during COVID-19 outbreak in China. J Anxiety Disord. 2020;74:102248. https://doi.org/10.1016/j.janxdis.2020.102248

24. Llewellyn S. Covid-19: how to be careful with trust and expertise on social media. BMJ. 2020;368:m1160. https://doi.org/10.1136/bmj.m1160 